\title{
CONSIDERAÇÕES SOCIOPSICOLÓGICAS SOBRE O PRECONCEITO: OS ELEMENTOS PSICODINÂMICOS E OS ELEMENTOS SOCIAIS
}

\author{
SOCIO-PSYCHOLOGICAL CONSIDERATIONS ABOUT THE PREJUDICE: \\ THE PSYCHODYNAMIC ELEMENTS AND THE SOCIAL ELEMENTS
}

\author{
Fabiana Pelinson ${ }^{1}$
}

Recebido em: 21/04/2016 Aprovado em: 05/12/2016

\section{RESUMO}

Este artigo objetiva descrever o preconceito a partir de uma perspectiva sociopsicológica, considerando os aspectos psicodinâmicos e sociais. Para isso, utilizam-se autores como Crochík (1995, 2001), Adorno (2000) e Amaral (1998). Entende-se que o preconceito é um fenômeno social, manifestado individualmente, de modo que o que leva o sujeito a desenvolver ou não preconceitos é a possibilidade de ter experiências e de refletir sobre si e sobre os outros nas relações sociais possibilitadas pelas instâncias sociais. Além disso, conclui-se que o preconceito diz mais respeito às necessidades do preconceituoso do que às características dos objetos de preconceito.

Palavras-chave: Preconceito; Psicologia; Sociologia;

\begin{abstract}
This article aims to describe the prejudice from a socio-psychological perspective, considering the psychodynamics and social aspects. For this, it is used different authors like Crochik (1995, 2001), Adorno (2000), Amaral (1998) and others. It is understood that prejudice is a social phenomenal individually manifested. In this way, what leads the subject to develop prejudices or not is the possibility of having experiences and thinking about themselves and others in social relations made possible by social instances. Furthermore, it is concluded that prejudice refers much more on the needs of prejudiced than the characteristics of prejudice objects.
\end{abstract}

Keywords: Prejudice; Psychology; Sociology; 


\section{Introdução}

As estruturas de organização das sociedades favoreciam, e ainda favorecem, manifestações insultuosas e segregacionistas de determinadas pessoas e grupos. $\mathrm{O}$ modo de organização da sociedade revela os valores, as normas e os princípios sociais que atuam sobre as ações, linguísticas e não linguísticas, dos indivíduos. As concepções a respeito do outro e suas formas de referência sobre esse outro nas construções linguísticas estão, conforme Santos (2012), impregnadas de atributos que esses valores e princípios lhes impõem. Isso quer dizer que as sociedades elaboram normas e valores que definem os atributos avaliados como aceitáveis ou indesejáveis em seus membros.

Em cada período histórico, os sujeitos exerceram um papel de hostilidade dirigida aos grupos considerados minoritários, revelando que a atitude da sociedade em relação a esses indivíduos pouco mudou. Embora a sociedade tenha evoluído em muitos aspectos, no que tange ao preconceito, ainda são cultivados antigos comportamentos que prenunciam o que nos parece ser um ciclo de repetição sem fim (CROCHÍK, 1995).

Diante do fenômeno do preconceito, oriundo de uma cadeia ritualística de contínuas repetições, cuja origem e cujo fim são quase impossíveis de fixar, Crochík (1995) acredita que pesquisar o preconceito é uma tarefa difícil, mas necessária, pois, ao discutir o tema, deve-se levar em conta a apropriação da realidade e a ação dos sujeitos frente a ela. Isso é necessário, porque uma das maneiras de lidar com o problema e entendê-lo como produto e produtor das intermediações entre subjetividade e sociedade é permitir que se fale dele, sobre ele e sobre nossos atos. Dessa forma, segundo Crochík (1995, p. 11), "somente quando pudermos reconhecer em nós mesmos a violência que criticamos no outro, poderemos dar início ao entendimento do problema".
Portanto, refletir sobre o preconceito é assumir a nossa própria desumanização e buscar modificá-la, é aceitar que não se constrói o mundo sozinho, é abrigar o outro como é e não como gostaríamos que fosse, é compreender cada indivíduo como único. Trata-se, desse modo, de analisar criticamente as relações sociais atuais e auxiliar na construção de uma sociedade menos desigual (MARTINS, 1998).

Dessa maneira, neste artigo, objetiva-se reunir informações acerca da questão do preconceito: os modelos teóricos que tentam explicar sua formação e a presença dos elementos psicodinâmicos e sociais envolvidos, a partir de uma perspectiva sociopsicológica. Para isso, utilizam-se as contribuições teóricas de autores como Crochík (1995, 2001), Adorno (2000) e Amaral (1998).

\section{Método de pesquisa}

Como o estudo proposto pretende apresentar um conceito de preconceito, a partir de uma perspectiva sociopsicológica, bem como seus elementos psicodinâmicos e sociais, optou-se por realizar uma pesquisa de cunho exploratório e descritivo. Esta pesquisa envolve, assim, uma abordagem interpretativa do objeto de estudo, de modo que a interpretação dos fenômenos e a atribuição de significados são básicas nesse processo. A investigação proposta é de cunho exploratório e descritivo, já que objetiva proporcionar maior familiaridade com o problema, com vistas a torná-lo mais explícito, e busca descrever os fatos e fenômenos de determinada realidade (GIL, 2007).

Em relação aos procedimentos e às técnicas de investigação, adota-se a pesquisa bibliográfica. De acordo com Marconi e Lakatos (2001), a pesquisa bibliográfica é caracterizada por um levantamento da bibliografia já divulgada em forma de livros, periódicos científicos, publicações avulsas em imprensa escrita e documentos eletrônicos, a 
fim de conhecer e analisar as principais contribuições teóricas já existentes, para ampliar o grau de conhecimento e informação sobre o assunto.

Qualquer investigação científica tem início com uma pesquisa bibliográfica; entretanto, existem pesquisas que se baseiam unicamente no levantamento bibliográfico, buscando referências teóricas publicadas, com o objetivo de recolher conhecimentos prévios sobre o problema a respeito do qual se procura a resposta. Desse modo, desenvolvida como um trabalho em si mesmo, e não apenas como uma etapa na elaboração do trabalho científico, a pesquisa bibliográfica, nesta investigação, permite o agrupamento, em uma única base de dados, de diversas informações que compõem uma base sólida para a descrição do preconceito e para a elaboração de pesquisas mais avançadas sobre o tema.

\section{Estudos sobre o preconceito}

Os estudos sobre o preconceito surgiram a partir da metade do século $\mathrm{XX}$, quando tiveram início conceitos e instrumentos sobre tal fenômeno social. Emergiu, então, uma nova forma de conceber o preconceito frente aos conflitos raciais, particularmente os existentes entre brancos e negros.

Antes da década de 1920, a história revelava a percepção, por parte de determinado grupo de pessoas, da suposta supremacia de uma raça e cultura. Os julgamentos das pessoas de cor branca sobre a inferioridade das pessoas de cor negra eram considerados uma percepção adequada da realidade, e não preconceito. As teorias, portanto, procuravam explicar essa suposta inferioridade dos negros.

Como argumenta Ferriols (2003),

As perguntas que guiam as investigações dos psicólogos sociais até os anos 20-30 têm menos haver com os estudos sobre o preconceito do que estabelecer o que diferencia uma raça de outra. Até este momento temos uma psicologia social das raças e não uma psicologia social do preconceito (FERRIOLS, 2003, p. 93).

Contudo, ao longo da década de 20, o preconceito começa a figurar como tema a ser estudado cientificamente. Contribui para esses novos estudos a ideia de que as discriminações contra as pessoas de grupos minoritários poderiam não estar fundamentadas em justificativas racionais e factuais (RODRIGUES et al., 2000).

De acordo com Crochík (1995, p. 75), o surgimento da crença na igualdade racial fez emergir a ideia de que as atitudes raciais negativas dos brancos em relação aos negros eram injustificáveis e injustas. Isso resultou no surgimento do conceito de preconceito, definido como atitudes intergrupais negativas injustificadas e fundamentalmente irracionais.

Paralelamente às tentativas de compreender e definir o preconceito, desenvolveram-se teorias ${ }^{2}$ que buscavam sintetizar os motivos das tensões e hostilidades intergrupais. As teorias ${ }^{3}$ clássicas da Psicologia estudam o preconceito como atitude universal, expressa em comportamentos depreciativos. Entretanto, nos últimos anos, o preconceito tem sido estudado a partir de uma perspectiva psicossocial, considerando as situações contextuais e culturais para sua manifestação.

Ao longo da história, as elucidações a respeito do preconceito debruçaram-se sobre aspectos psicodinâmicos (ADORNO et al., 1969; DOLLARD et al., 1939), diferenças individuais (ADORNO et al., 1969), aspectos cognitivos (ROKEACH, 1960) e aspectos socioculturais (PETTIGREW, 1958).

Crochík (1995) entende que as diversas teorias sobre o preconceito não são conflitantes entre si, mas complementares, pois cada uma estuda e revela um fator específico relacionado à gênese do

2 Como a Teoria da Frustração-agressão, da Personalidade Autoritária e do Espírito Fechado (DOLLARD et al., 1939; ADORNO et al., 1969; ROKEACH, 1960).

3 Como as teorias de Adorno et al. (1969) e Rokeach (1960). 
problema. Por isso, baseado nas ideias de Duckitt (1992), Crochík (1995) propõe o seguinte agrupamento das teorias:

1. Teorias que consideram o preconceito a partir das teorias Psicodinâmicas e o explicam como produto de mecanismos de defesa que são utilizados frente à frustração e a privação. Ou seja, os sujeitos frustrados socialmente reagiriam hostilmente contra as minorias, utilizando-se de mecanismos de defesa, que encobririam seus conflitos internos. Como estes processos psicológicos são universais, potencialmente todos poderiam desenvolvê-lo. Esta teoria ficou conhecida também, como a teoria do "bode expiatório";

2. Teorias que consideram o preconceito como uma manifestação de perturbações psíquicas de determinadas estruturas de personalidade. Ou seja, alguns indivíduos teriam formado ao longo de seu desenvolvimento uma estrutura de personalidade predisposta ao preconceito;

3. Teorias que consideram o preconceito um problema da socialização, isto é, os indivíduos se conformariam às normas e valores culturais transmitidos, e, assim, bastaria alterar os próprios processos de socialização, no que diz respeito ao seu conteúdo, para que o preconceito deixasse de existir;

4. Teorias que consideram o preconceito relacionado aos conflitos de interesses entre grupos sociais. Ele seria devido à própria configuração social; 5. Teorias que consideram o preconceito como um problema cognitivo. $\mathrm{O}$ indivíduo para entender o mundo o simplifica através de estereótipos ou processos cognitivos que categorizam os fenômenos para que eles possam ser entendidos pelos sujeitos. Assim, ele seria um fenômeno universal (CROCHÍK, 1995, p. 76-77).

Assim, entre as décadas de 1930 e 1950, as principais preocupações da Psicologia situavam-se na busca por estruturas universais, valorizando os elementos psicológicos e individuais. Durante esse período, as teorias acerca do preconceito podem ser situadas no nível da análise intrapessoal e interpessoal.

Já durante os anos 1960 e 1970, a perspectiva sociocultural foi dominante. Os estudos desenvolvidos nesse período centravam-se na ideia de que a origem do preconceito está nas normas sociais dominantes em cada lugar e momento histórico (DUCKITT, 1992). Nesse momento, ocorre uma interligação de fatores sociológicos e psicológicos para a construção de concepções teóricas adequadas para explicar o fenômeno. Dentro desse período, duas fases distinguem os estudos quanto às causas do preconceito: a ênfase na influência normativa no começo dos anos 60; e a preocupação com as dinâmicas intergrupais e os conflitos de interesse entre grupos por volta da década de 70. Esses níveis de análise configuram as últimas classificações teóricas de Crochík (1995).

É perceptível, dessa forma, que diversas abordagens se sucederam cronologicamente e coexistiram, apresentando elementos conceituais muitas vezes complementares para compreender o preconceito. Cada conceituação derivou de uma maneira própria de explicar o fenômeno, e todas elas estavam marcadas por tendências provocadas por eventos históricos que repercutiam nas pesquisas científicas (DUCKITT, 1992). Aqui, a explanação dessas teorias teve como propósito apenas demonstrar como o preconceito foi teorizado nos estudos mais tradicionais sem, de fato, examinar todas as perspectivas, nem tampouco discutir a própria categorização.

Portanto, a partir de uma compreensão de como o preconceito vem sendo analisado, optou-se por apresentar as contribuições teóricas de Crochík (1995, 2001), que propõe uma interligação de fatores sociológicos e psicológicos para a compreensão do fenômeno, tendo em vista, com maior ou menor ênfase, todos os parâmetros das teorias supracitadas.

A partir de um olhar sociopsicológico sobre o indivíduo e a sociedade, Crochík edifica suas concepções sobre o preconcei- 
to e propõe uma perspectiva psicossocial, considerando as situações contextuais e culturais para a manifestação desse fenômeno. Contudo, como, neste trabalho, não se pretende encerrar uma definição absoluta de preconceito, propõe-se discorrer sobre as formas como Crochík articula suas contribuições teóricas.

As produções de Adorno e Horkheimer referenciadas por Crochík $(1995,2001)$ refletem a orientação teórica da primeira geração da Escola de Frankfurt, fase de uma crítica da sociedade inspirada em Freud e Marx ${ }^{4}$. O principal estudo referenciado, intitulado "A personalidade autoritária", é considerado um clássico para a Psicologia Social, devido ao seu caráter interdisciplinar $^{5}$ e à utilização de meios empíricos diversos, como escalas de altitudes, entrevistas e testes projetivos. Crochíck, a partir de um olhar sociopsicológico, baseia-se nesses autores para compor suas proposições teóricas, os quais mostram que o fenômeno do preconceito não pode ser explicado por uma imputação de culpa apenas ao indivíduo, mas, também, à cultura ${ }^{6}$ e à sociedade, que criam e mantêm o preconceito.

\section{Indivíduo, sociedade e preconceito: considerações sociopsicológicas}

Baseado nas considerações e nos resultados de Adorno et al. (1969)7, 4 No âmbito da sociologia alemã, surge a chamada Teoria Crítica com a formação da Escola de Frankfurt e do Instituto de Pesquisas Sociais. A primeira geração de cientistas sociais que integrou a Escola era composta de Walter Benjamin, Theodor Adorno, Max Horkheimer, Herbert Marcuse, dentre outros. Em seu aspecto geral, a Teoria Crítica está baseada em uma abordagem materialista - de caráter marxista e multidisciplinar - da sociedade industrial e dos fenômenos sociais contemporâneos. A primeira geração de cientistas pertencentes à Escola desejava que todo conhecimento social produzido no Instituto transbordasse para fora do círculo acadêmico e produzisse intervenções práticas sociais, provocando mudanças ou transformações na sociedade.

5 Participaram do estudo pesquisadores de diversas áreas científicas, como Comunicação, Psicologia, Filosofia e Antropologia.

6 A partir da perspectiva de Williams (1992), cultura é entendida como uma força produtiva, essencial na produção de nós mesmos e da sociedade. A cultura é processo, produção e produto da sociedade, figurando "como um sistema de significações realizado" (1992, p. 206). Portanto, neste estudo, a cultura não é vista como uma entidade monolítica ou homogênea, mas, ao contrário, manifesta-se de maneira diferenciada em qualquer formação social ou época histórica. Isto é, todas as culturas são híbridas, heterogêneas, extraordinariamente diferenciadas, e não monolíticas. Dessa forma, a cultura não significa simplesmente sabedoria recebida ou experiência passiva, mas um grande número de intervenções ativas.

7 A perspectiva teórica utilizada como a base de Crochík para compreender o preconceito tem como pano de fundo a pesquisa intitulada "A personalidade autoritária", desenvolvida por Adorno, Frenkel-Brunswik, Levinson e Sanford na década de 40. Segundo Carone (2012), os
Crochík propõe uma perspectiva psicossocial para compreender o preconceito, considerando os aspectos objetivos, como as situações contextuais e os valores sociais, mas também os elementos subjetivos. Essa compreensão se apoia nas palavras de Adorno e Horkheimer (1973) ao considerarem que,

As grandes leis do movimento social não regem por cima das cabeças dos indivíduos, realizando-se sempre por intermédio dos próprios indivíduos e de suas ações. A investigação sobre o preconceito tende a reconhecer a participação do momento psicológico nesse processo dinâmico em que operam a sociedade e o indivíduo (ADORNO E HORKHEIMER, 1973, p. 173-174).

Um dos principais resultados a que os autores chegam é que a formação da personalidade predisposta ao preconceito está totalmente ligada à cultura e que o preconceito diz mais respeito às necessidades do preconceituoso do que às características dos objetos de preconceito. Portanto, o preconceito é formado durante o processo de socialização e é constituído de raízes sociais e psicodinâmicas.

Embora os elementos psicodinâmicos e sociais se interinfluenciem e se inter-relacionem, optou-se, neste estudo, por fazer uma separação entre esses elementos por meros fins didáticos.

4.1 Elementos psicodinâmicos na formação do preconceito

O estudo desenvolvido por Adorno et al. (1969) confirma a hipótese de que o antissemitismo e o preconceito de modo geral se relacionam com a discriminação a outros grupos, fazendo parte

estudos desses teóricos se preocuparam, entre outras coisas, em descobrir em cidadãos comuns, não participantes de organizações fascistas, traços essenis e biśricos do fascismo latente $\mathrm{O}$ cstudo teve como

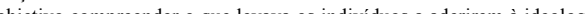
fascista e a tomarem atitudes violentas influenciadas pelo preconceito contra judeus. Para isso, os autores utilizaram instrumentos inspirado na psicologia social e na psicologia clínica de orientação psicanalítica A partir desse estudo, Crochík propõe uma visão sociopsicológica para compreender o preconceito. 
de uma configuração ideológica mais ampla. Nesse estudo, os autores afirmam que o antissemitismo tem menos relação com o judeu do que com as representações que os antissemitas fazem dele (CROCHIK, 1995).

Em outros termos, a falsa projeção, enquanto essência e fundamento psíquico do preconceito, manifesta a incapacidade de o sujeito diferenciar no material projetado o que lhe é de fato característico e o que não é. Portanto, o preconceito tem pouca ou nenhuma relação com o objeto vítima do preconceito.

Segundo Adorno e Horkheimer (1986), a projeção é necessária à percepção e ao pensamento. Logo, a projeção e seu controle permitem a diferenciação entre sujeito e objeto, e, quando um desses elementos é eliminado, ocorre a falsa projeção.

A falsa projeção pode expressar-se por meio da anulação do objeto ou da anulação do sujeito. A anulação do objeto ocorre quando o indivíduo projeta sem limites. Nessa situação, qualquer objeto é reduzido ao sujeito, porque o que está fora dele é percebido como ameaçador e o faz controlar tudo o que existe (ADORNO et al., 1969). Já a anulação do sujeito ocorre quando a projeção é negada e passa a se render tributos à realidade tal como ela se apresenta, dispensando a necessidade de refletir sobre ela. Essas são, portanto, duas formas de falsa projeção, perceptíveis nos indivíduos estudados pela pesquisa de Adorno et al. (1969) e comentadas por Crochík (1995):

\footnotetext{
A anulação do objeto pela projeção é exemplificada por aqueles que atribuem características suas que não pode reconhecer enquanto tais sobre o judeu, a anulação do sujeito se dá através do convencionalismo apresentado como uma das características de vários sujeitos, que consiste na adesão, sem reflexão aos costumes e ideias vigentes para que o sentimento da fragilidade do ego possa ser compensada pela aceitação social (CROCHÍK, 1995, p. 100).
}

A falsa projeção é, portanto, um mecanismo que o indivíduo utiliza para se livrar dos impulsos que ele não admite como seus e atribui - imaginariamente - ao outro. Dessa forma, como o conteúdo da falsa projeção não corresponde à realidade, tanto as opiniões quanto os comportamentos desses indivíduos possuem um caráter irracional.

Desse modo, é possível entender como ocorre o processo pelo qual passa o sujeito com predisposição ao preconceito. Inicialmente, o indivíduo identifica-se com o alvo do preconceito, mas aquilo que deseja ser ou ter é censurado e proibido; esse desejo é negado e projetado no outro, que passa a ser alvo de perseguição e preconceito, como uma forma de reduzir a ansiedade resultante da identificação.

Existem algumas complicações intrínsecas ao conceito de preconceito. Uma delas refere-se à tendência do vivente de desenvolver preconceitos por diversos objetos, como ao negro e ao homossexual, por exemplo. Isso indica, de acordo com Crochík (1995), uma forma de atuação do preconceituoso que independe das características apresentadas pelos objetos alvos de preconceito, isto é, o indivíduo desconsidera as características distintas apresentadas pelo outro.

Apesar de certa tendência em apresentar preconceito por diversos indivíduos, o conteúdo desse preconceito em relação aos objetos não é semelhante entre si, pois os estereótipos de que o sujeito se utiliza são distintos para cada objeto do preconceito ${ }^{8}$. O que o sujeito imaginariamente percebe como sendo o negro não é o mesmo que imagina ser o homossexual, e assim por diante.

A relação entre a identificação das particularidades do preconceituoso e a diversidade de conteúdos que este percebe em suas vítimas expõe a relação entre indivíduo e sociedade, porque:

a fixidez de um mesmo tipo de comportamento se relaciona com estereó-

8 Como o negro ser "o ladrão ou o bandido", o mulçumano ser "o terrorista", o índio ser "o preguiçoso", entre outros. 
tipos oriundos da cultura, que embora se diferenciem em cada objeto, não se confundem com eles; é dizer, à aparente diversidade que a roupagem dos estereótipos culturais reveste os seus objetos, corresponde uma fixidez de comportamento no preconceituoso. Esta relação não é direta, pois o indivíduo, se apropria e modifica os estereótipos de acordo com as suas necessidades, contudo, as ideias sobre o objeto do preconceito não surgem do nada, mas da própria cultura (CROCHÍK, 1995, p. 17).

Desse modo, o pensamento estereotipado é construído culturalmente e está fundado em uma fixidez do comportamento. Infere-se, portanto, que o preconceito está ligado à cultura.

4.2 Elementos sociais na formação do preconceito

Por entender o preconceito como um fenômeno social que apresenta aspectos objetivos e subjetivos, Crochík (1995) pondera que, embora seja um evento manifestado individualmente, o que faz o indivíduo ser preconceituoso pode ser localizado no seu processo de socialização, como respostas aos conflitos gerados nesta ação. Em outros termos, o processo de socialização, que permite ao indivíduo se constituir e se transformar, também é responsável pelo desenvolvimento de preconceitos.

Crochík (1995) considera o processo de socialização como fruto da cultura e da história. Isso quer dizer que as formas de socialização são diferentes para todas as sociedades, uma vez que cada organização social possui sua própria cultura e uma maneira específica de construí-la. No processo de socialização, os viventes formam e são formados pela sociedade e, portanto, são preparados para participar dos sistemas sociais, o que implica a interação social entre o vivente e a sociedade que o rodeia.

Gomes (1990) assinala que, no processo de socialização, a criança domina o mundo social circundante, incorpora os papéis sociais básicos seus e de outros, presentes e futuros - e constrói as características fundamentais de sua personalidade e identidade. Dessa forma, na visão de Crochík (1995), o que leva o sujeito a desenvolver preconceitos ou não é a possibilidade de ter experiências e de refletir sobre si e sobre os outros nas relações sociais possibilitadas pelas instâncias sociais - como a família, a escola e os meios de comunicação. Como experiência e reflexão são as bases constituintes do sujeito na sua relação com a cultura, sua ausência caracterizaria o preconceito.

Para o autor, a ação imediata e sem reflexão marca uma atitude ou um comportamento preconceituoso. Isto é, o preconceituoso apresenta uma reação congelada frente ao seu indivíduo alvo. Diante de uma pessoa que nos é "estranha" ou "diferente", busca-se disfarçar o desconforto ou justificá-lo para desculpar a reação negativa. Por isso, Crochík (1995) pressupõe que existem duas formas de reação frente à pessoa "diferente": o exagero de aceitação e a rejeição.

Às vezes, a reação assume um exagero de aceitação, caracterizada por frases ou atitudes que objetivam dar um consolo antecipado à pessoa em questão. Essa complacência se aproxima da polidez, que funciona como um verniz civilizatório, desenvolvido por uma falsa educação que não permite a manifestação espontânea da estranheza frente ao outro, ou da não manifestação de estranheza alguma, se, desde a infância, fosse desenvolvida a curiosidade, e não a rejeição frente às pessoas "diferentes" (CROCHÍK, 1995).

Amaral (1998) demonstra que reconhecer a diferença do outro - ou nossa rejeição a ela - causa mal-estar e tensão, motivo pelo qual os indivíduos acionam mecanismos de defesa da negação, que podem se revestir de roupagens específicas, tais como compensação, simulação e atenuação. Quando pronunciamos frases 
do tipo "É cego, mas tão inteligente", estamos compensando uma característica ou condição que consideramos anormal e, dessa forma, "negando-a ao contrapô-la a um atributo desejável - o "mas" denuncia esse movimento" (AMARAL, 1998 , p. 20). A atenuação pode ser ilustrada em frases como: "Não tem visão, mas podia ser pior" ou, então, "Não tem um braço, e podia não ter os dois". Nesses casos, nega-se, pela atenuação, a especificidade de uma condição ou característica. Já a simulação ocorre quando se nega literalmente a diferença, fazendo de conta que aquela característica ou condição não existe: "É cego, mas é como se não fosse".

Amaral (1998) explica que o preconceito, principalmente aquele direcionado às pessoas com deficiência, também aparece na forma de generalização indevida, correlação linear e contágio osmótico. A generalização indevida ocorre quando se considera que a pessoa com deficiência é aquela condição específica e nada mais. Nesse sentido, um indivíduo com deficiência auditiva, por exemplo, tem como único atributo a deficiência e tem sua deficiência generalizada, passando a ser considerado também com deficiência visual, física etc. A correlação linear é a lógica do "se... então": se esta atividade é boa para essa pessoa com deficiência, então é boa para todas as pessoas com deficiência. A esse respeito, Amaral (1998, p. 17) cita o seguinte exemplo: "Se a audição é um sentido privilegiado no cego (claro que aqui há mais um preconceito), então os cegos são excelentes músicos". E, por fim, o contágio osmótico refere-se ao medo de "contaminação" pelo convívio com o outro.

O fato é que, conforme Amaral (1998), aceitar exageradamente o outro ou utilizar-se desses mecanismos faz com que se continue a sofrer com a ansiedade na relação interpessoal. Crochík (1995) acrescenta ainda que, de imediato, pressupomos que é uma situação difícil de ser vivida e sofremos a aparência da dor que nos impede tanto de senti-la quanto de experienciarmos a relação sem tabus.

A outra forma de ação frente à pessoa "diferente" é a de rejeição, que ocorre quando não se dá valor àquela pessoa ou, então, concede-se um valor preconcebido, inferior e estereotipado. A rejeição contém a insensibilidade do indivíduo, que, para aprender a ser forte, despreza toda forma de fragilidade, inclusive a sua. Segundo Crochík (1995, p. 20), "a educação que nos leva a seguir rigidamente as regras estabelecidas, ou seja, que nos obriga a sermos duros conosco, nos leva a sermos duros com os outros".

Em ambas as reações, o indivíduo preconceituoso não consegue ver que a sua reação encontra respaldo em si mesmo e que a falta de reflexão e experiências traz consigo a necessidade de defesa em relação àqueles que causam certa estranheza. Além disso, essas duas atitudes não são inatas, mas desenvolvidas.

Como o preconceito não é inato nos indivíduos, ocorre a interferência dos processos de socialização que forçam o sujeito a se modificar para se adaptar. Desse modo, a criança já recebe ideias preconcebidas sobre determinados indivíduos ou grupos. Na transmissão da cultura para as novas gerações, também são transmitidos preconceitos na forma de ideias ou concepções que devem ser assumidas como próprias, sem que haja reflexão sobre sua racionalidade.

A superioridade que o preconceituoso sente em relação ao objeto vítima do preconceito também tem estreita relação com a cultura. Essa sensação de superioridade é solicitada por uma cultura que não permite um lugar fixo a ninguém - trata-se, conforme Crochík (1995, p. 61), da eterna luta de todos contra todos que a sustenta. Assim, ter poder sobre o indivíduo considerado mais fraco representa a busca por um espaço em uma sociedade que gira em torno do poder.

Por outro lado, quanto menos os indivíduos se reconhecem com a cultura 
a que pertencem, maior é sua necessidade de se identificarem com ela para aliviar o sentimento de desamparo, o que acarreta um conflito entre a necessidade de adaptação às normas e aos valores que os indivíduos não reconhecem como seus e suas próprias vontades e interesses:

A presença de preconceitos, portanto, revela uma cultura dissociada de seus membros, revelando, a sua irracionalidade, uma vez que a cultura só pode existir em função dos interesses daqueles; esta mesma irracionalidade, contudo, aparece do lado do indivíduo: a violência sutil ou manifesta exercida pelo preconceituoso é a resposta a uma violência sutil ou manifesta gerada inicialmente pela cultura. Mas, este argumento não deve desresponsabilizar o preconceituoso de seus atos, mas, auxiliar a entender a sua gênese (CROCHÍK, 2001, p. 61).

Dito de outro modo, a falta de pertencimento e identificação do indivíduo à cultura influencia a presença de preconceitos nos sujeitos. Com relação à sociedade, Crochík (1995) compreende que a regulamentação exagerada, característica de uma sociedade que tudo deve administrar, reflete a dificuldade que os indivíduos têm de agir conforme sua própria consciência. Por sua vez, essa necessidade de obedecer a uma ordem externa leva "à constituição de indivíduos frágeis com uma insegurança constante, que suscita o preconceito para se afirmar uma identidade que não se possui" (CROCHÍK, 1995, p. 65). Sendo assim, em uma sociedade competitiva e individualista, toda ação que incentive o confronto com o outro colabora com a regressão social e individual, que são os componentes básicos do preconceito. $\mathrm{O}$ preconceito prepara a ação da exclusão do mais frágil, por parte daqueles que não podem viver a sua fragilidade, em uma cultura que privilegia a força.

O estereótipo, por exemplo, é formado por esse conjunto de predicados que são atribuídos pela sociedade a determinado grupo ou indivíduo. $\mathrm{Na}$ sociedade atual, o padrão e/ou ideal é o homem adulto, branco, heterossexual, de classe média urbana, forte e independente; os outros são descritos pelas diferenças em relação a esse tipo "ideal".

As principais características do atual sistema de produção, a competitividade e a utilidade, trazem esse modelo de homem, que é aquele que corresponde à produtividade exigida pelo sistema. A cultura legitima esse modelo de homem e transforma em "diferentes" os que não se enquadram nele. Assim, sempre que surge um novo modelo de normalidade, novos alvos de preconceito são construídos. Exatamente por isso, Adorno (2000) afirma que a velocidade das mudanças sociais dificulta que o indivíduo consiga modificar sua consciência pela incorporação do novo ao velho. Não há tempo para a percepção das mudanças no objeto e para uma consequente mudança no indivíduo.

Adorno (2000) cita a frieza e a indiferença como principais características das relações entre os homens na atualidade. Os indivíduos têm dificuldade de amar e parar de se defender diante dos outros em uma sociedade que incentiva o culto ao "eu" e às relações individualistas, nas quais o "outro" aparece apenas como elemento figurativo. A competitividade da sociedade atual favorece relações hostis e de anulação do outro. Dessa forma, só a transformação social que elimine ou, então, minimize a necessidade de competição e fortaleça a cooperação é capaz de eliminar o preconceito.

Do mesmo modo, Amaral (1998) ressalta que, em uma sociedade que tipifica, padroniza e classifica o ser humano em categorias fixas e rígidas, as relações sociais são marcadas pelo maniqueísmo da plenitude versus falha, perfeição versus imperfeição e eficiência versus ineficiência. A sociedade estabelece os meios de categorizar as pessoas e os atributos considerados comuns para os membros de cada uma das categorias. Ao eleger um modelo a ser 
seguido, atribui-se a ele tudo que é positivo e avalia-se o restante como negativo, com preconcepções e estereótipos.

Em resumo, o conceito de preconceito é compreendido aqui, por um olhar sociopsicológico, como resultado de um processo de socialização, de modo que o que leva o sujeito a desenvolver ou não preconceitos é a possibilidade de reflexão e experienciação nas relações sociais.

Cabe afirmar, ainda, que as duas formas de reação frente à diversidade, o exagero de aceitação e a rejeição, podem ser polarizadas em equivalentes como polidez e impolidez. Isso significa dizer que os comportamentos polidos também estão presentes no fenômeno do preconceito. Além disso, o conceito de estigma $^{9}$ e estereótipo parece ter força para ampliar essa questão, pois o estigma marca negativamente quem possui determinados atributos, considerados socialmente como indesejáveis, assim como os estereótipos são elementos do preconceito que ambicionam impedir qualquer flexibilidade de pensamento, agindo, inclusive, a serviço do status quo na manutenção das relações de poder, desigualdade e exploração.

\section{Considerações finais}

Diversas abordagens teóricas coexistiram apresentando conceituações e reflexões para a compreensão do preconceito. Se, antes da década de 1920, tinha-se uma psicologia social das raças, e não uma psicologia social do preconceito, ao longo dessa mesma década o preconceito passa a ser objeto de estudos científicos.

Entre 1930 e 1950, as teorias sobre o preconceito situam-se no nível da análise intrapessoal e interpessoal, e, nas décadas de 1960 e 1970, a perspec-

9 O estigma corresponde, segundo Goffman (1988), a atributos, vistos socialmente como diferenças indesejáveis e estranhas, que marcam, negativamente, quem as possui. $\mathrm{O}$ autor entende essas diferenças sob a perspectiva social, de modo que as sociedades definem quais características são avaliadas como aceitáveis ou indesejáveis em seus membros. Ainda de acordo com Goffman (1988), o estigma é uma relação entre atributo e estereótipo e tem sua origem relacionada à construção social dos significados por meio da interação. Ou seja, a sociedade determina um padrão externo ao sujeito que permite prever sua categoria e seus atributos. tiva sociocultural é a dominante. É nesse período que ocorre uma interligação de aspectos psicológicos e sociológicos para a construção de concepções teóricas a respeito do preconceito.

A partir de um breve histórico sobre esses estudos, entende-se que a perspectiva apresentada por Crochík (1995, 2001) propõe uma interligação de fatores sociológicos e psicológicos e considera os parâmetros de diversas teorias que se sucederam cronologicamente. Nesse sentido, por levar em consideração aspectos objetivos, como as situações contextuais e os valores sociais, e aspectos subjetivos, o autor apresenta uma abordagem importante para uma compreensão crítico-reflexiva do preconceito.

Uma das principais contribuições revisitadas e comentadas por Crochík é que a formação da personalidade predisposta ao preconceito está totalmente ligada à cultura. Portanto, o preconceito é formado durante o processo de socialização, sendo constituído de raízes sociais e psicodinâmicas.

Além disso, o autor apresenta a competitividade e a individualidade como elementos sociais que incentivam o confronto com o outro e a exclusão do mais "frágil", já que a cultura atual privilegia a força. No sistema de produção, cria-se um modelo de homem que corresponde à produtividade exigida pelo sistema. Desse modo, a cultura legitima esse modelo de homem e transforma em "diferentes" os que não se enquadram nele.

Portanto, entende-se que as considerações sociopsicológicas, especialmente as elaboradas por Crochík, têm potencial para aprofundar e problematizar as questões que envolvem o preconceito, embora seja necessário esclarecer que as análises, teóricas ou empíricas, são sempre parciais e incompletas, pois envolvem escolhas e olhares do pesquisador sobre o objeto. Assim, não há um modelo pronto e completo que envolva todos os aspectos desse fenômeno, pois outros olhares sempre permitem complementariedades. 


\section{Referências}

ADORNO, T. Educação após Auschwitz. In: ADORNO, T. Educação e emancipação. 3. ed. São Paulo: Paz e Terra, 2000. cap. 6, p. 119-139.

ADORNO, T., FRENKEL-BRUNSWIK, E., LEVINSON, D. \& SANFORD, N. The authoritarian personality. New York: WW Norton, 1969.

ADORNO, T. \& HORKHEIMER, M. Temas básicos de sociologia. São Paulo: Cultrix, 1973.

AMARAL, L. A. Sobre crocodilos e avestruzes: falando de diferenças físicas, preconceitos e sua superação. In: GROPPA, J. (Org.). Diferenças e preconceitos na escola: alternativas teóricas e práticas. São Paulo: Summus, 1998. p. 11-30.

CARONE, I. A personalidade autoritária: estudos frankfurtianos sobre o fascismo. Revista Sociologia em Rede, v. 2, n. 2, p. 14-21, 2012.

CROCHÍK, J. L. Preconceito, indivíduo e cultura. São Paulo: Robe Editorial, 1995.

Teoria Crítica da Sociedade e Estudos sobre o preconceito. Revista Psicologia Política, v. 1, n. 1, p. 67-99, 2001.

DOLLARD, J., DOOB, L., MILLER, N., MOWRER, O. \& SEARS, R. Frustration on aggression. New York: Yale University Press, 1939.

DUCKITT, J. H. Psychology and prejudice: a historical analysis and integrative framework. EUA: American Psychologist, 1992.

FERRIOLS, B. C. El prejuicio hacia las minorias: el caso de los gitanos. Espanha, 2003. Tese (Doutorado em Psicologia) - Faculdade de Psicologia, Universidade de Valência.

GIL, A. C. Como elaborar projetos de pesquisa. 4. ed. São Paulo: Atlas, 2007.
GOFFMAN, E. Estigma: notas sobre a manipulação da identidade deteriorada. Rio de Janeiro: Guanabara, 1988.

GOMES, J. V. Socialização: um problema de mediação? São Paulo: Psicologia/USP, 1990.

MARCONI, M. de A. \& LAKATOS, E. $M$. Metodologia do trabalho científico. São Paulo: Atlas, 2001.

MARTINS, M. M. Reflexões sobre preconceito: em busca de relações mais humanas. Revista InterAÇÃO, v. 2, p. 9-27, 1998.

RODRIGUES, A., ASSMAR, E. M. L. \& JABLONSKI, B. Psicologia social. Petrópolis: Vozes, 2000.

ROKEACH, M. The open and closed mind. New York: Basic Books, 1960.

SANTOS, J. H. V. Polidez e inclusão: o "ser" e o "parecer" no discurso de professores sobre a inclusão da pessoa com deficiência na escola. Sergipe, 2012. Dissertação (Mestrado em Letras) - Setor de Letras, Universidade Federal de Sergipe.

WILLIAMS, R. Cultura. Rio de Janeiro: Paz e Terra, 1992. 